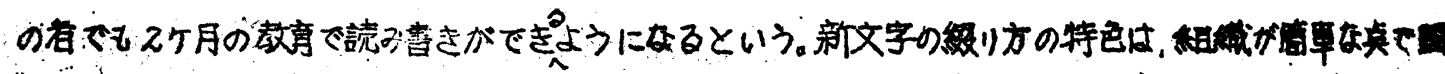

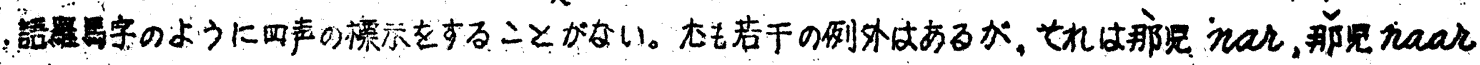

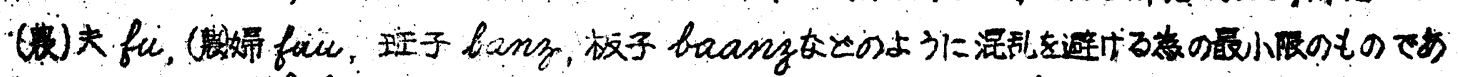

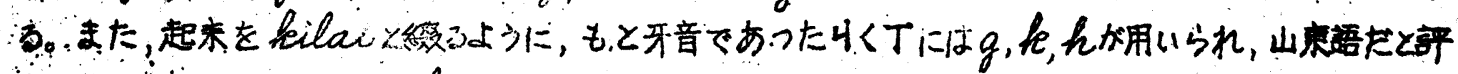

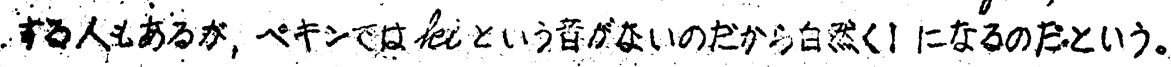

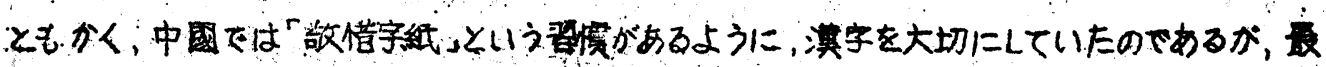

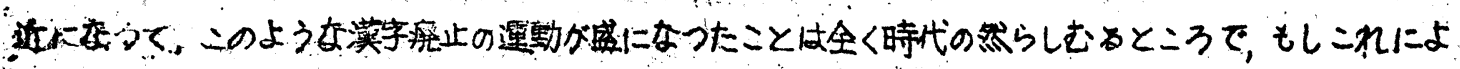

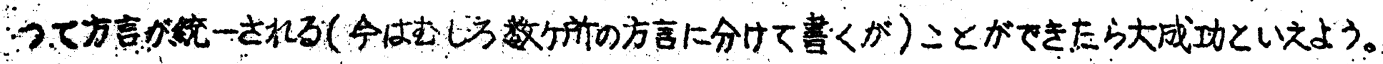

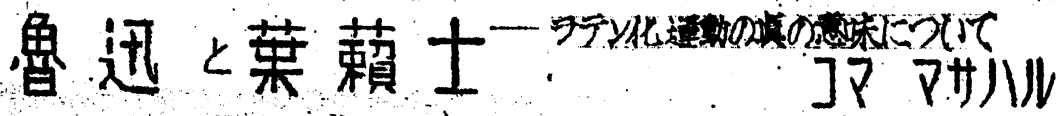

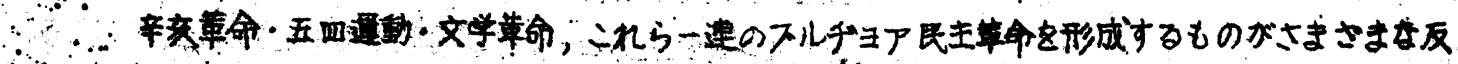

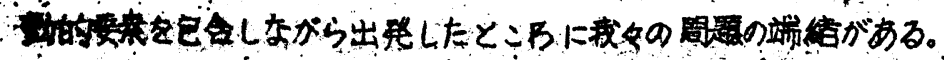

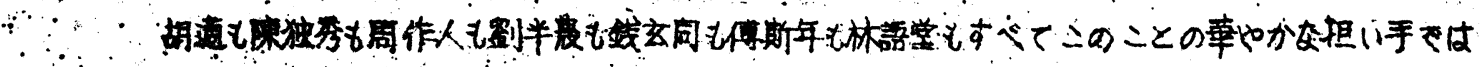

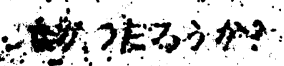

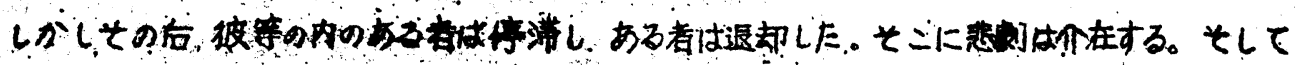

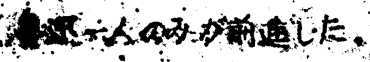

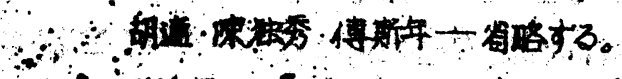

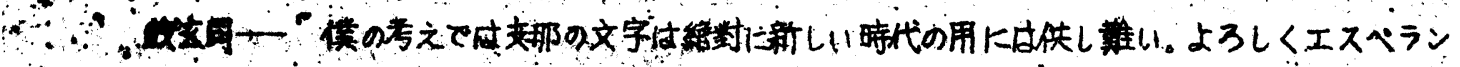

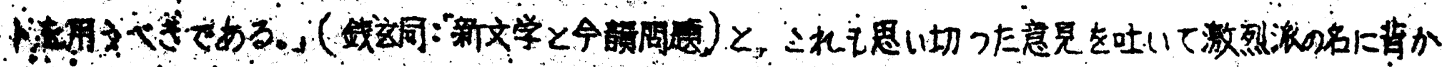

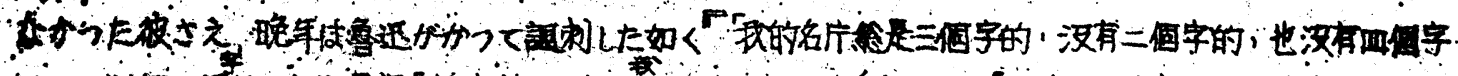

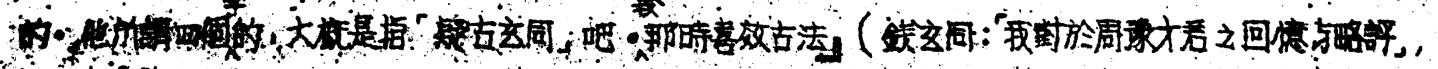

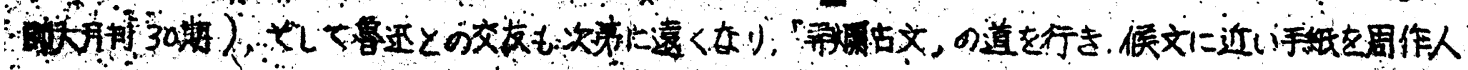

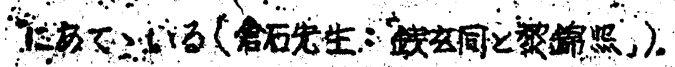

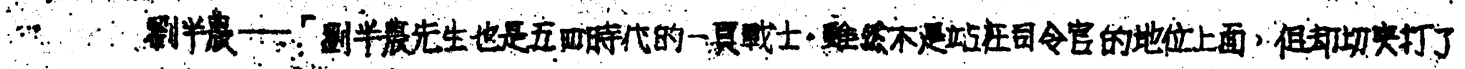

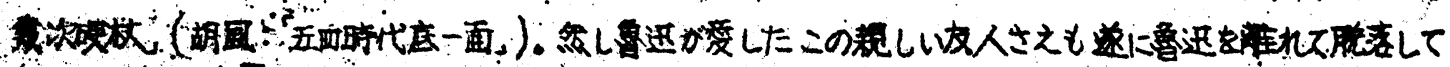

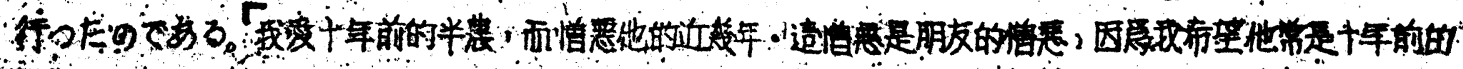

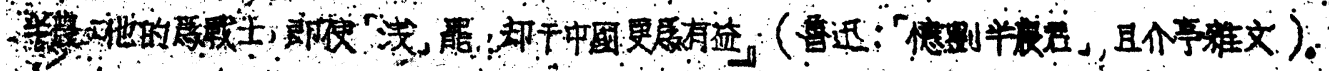

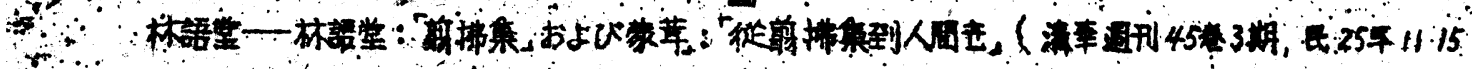

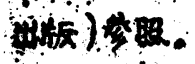

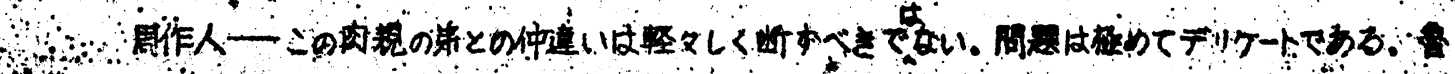

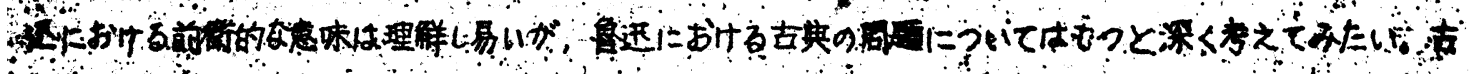

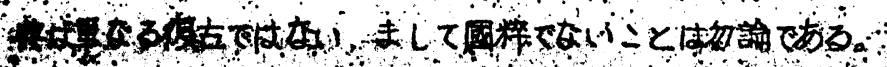

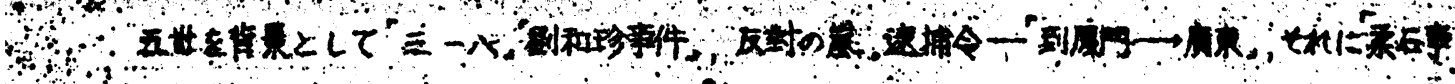
अ 


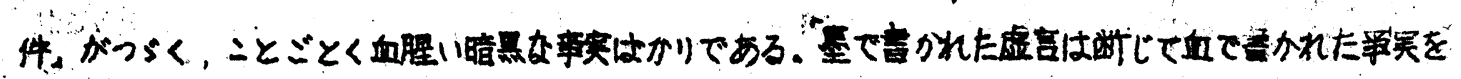

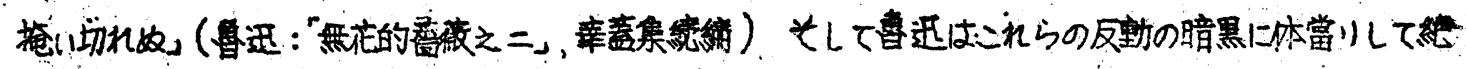

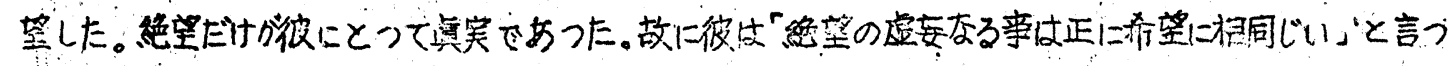

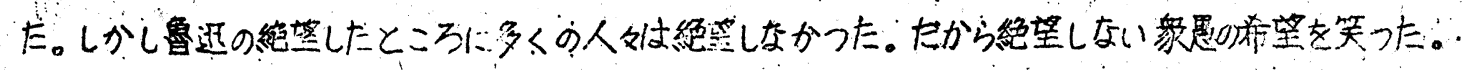

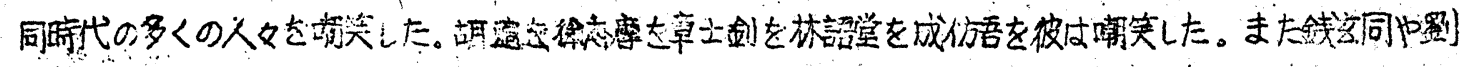

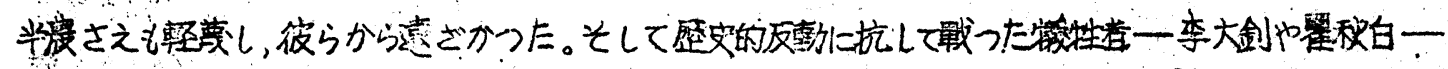

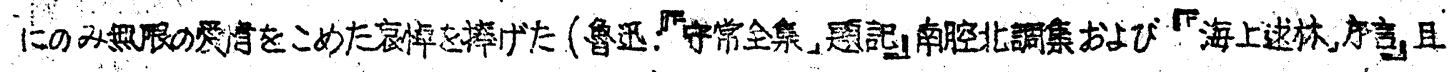

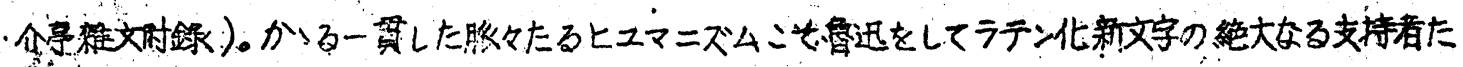

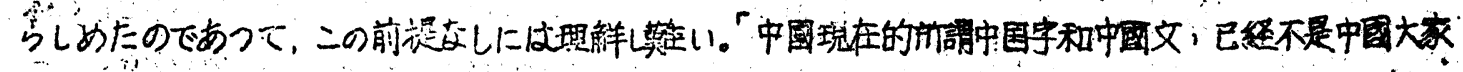

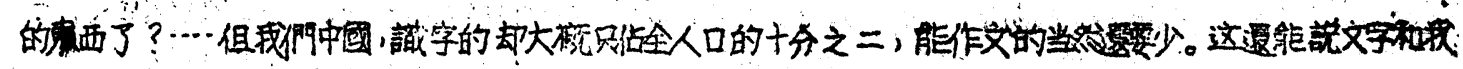

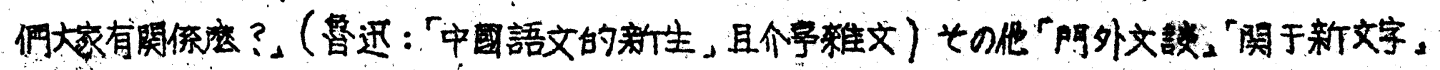

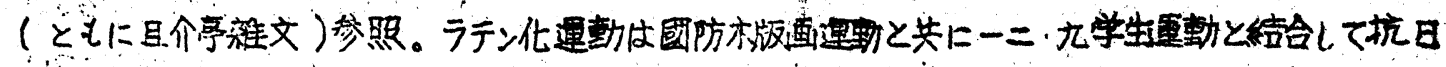

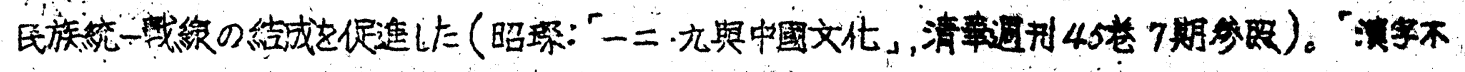

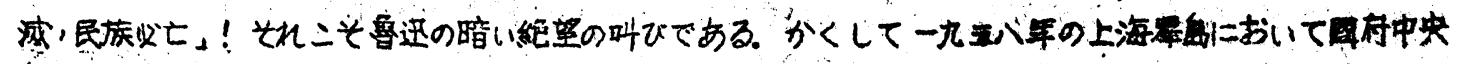

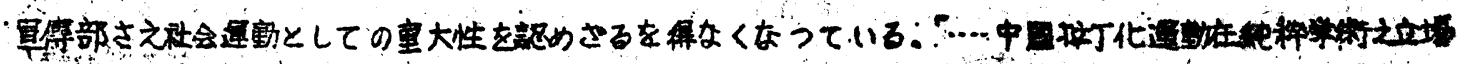

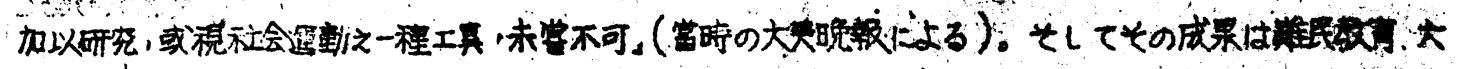

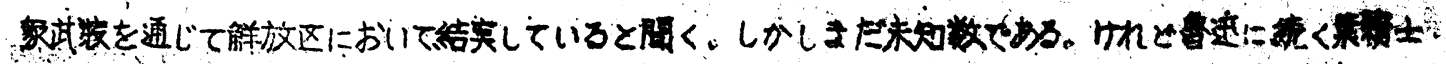

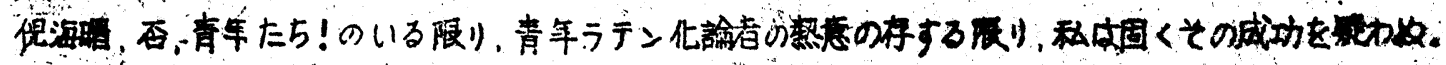

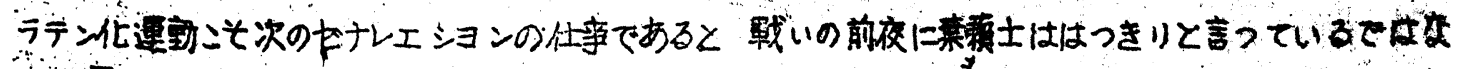

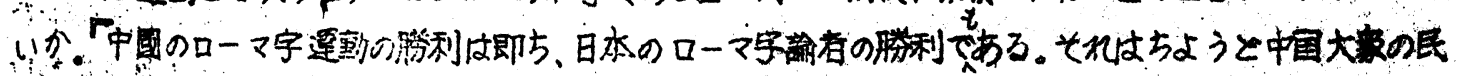

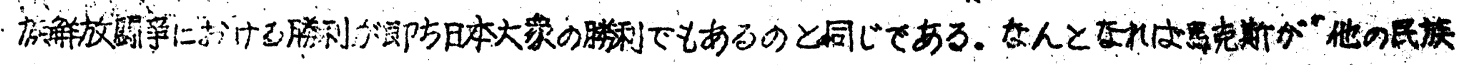

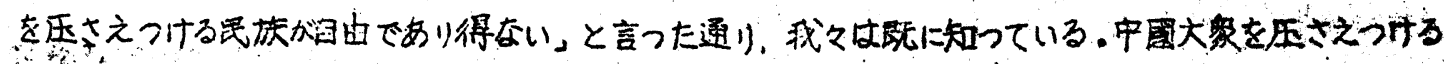

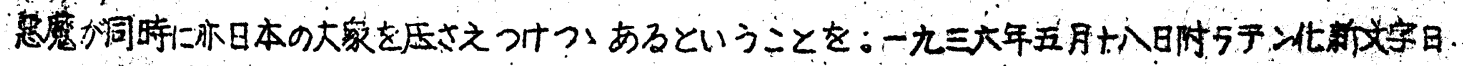

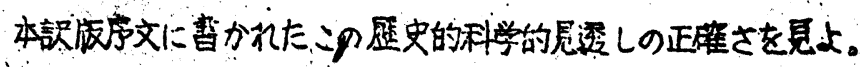

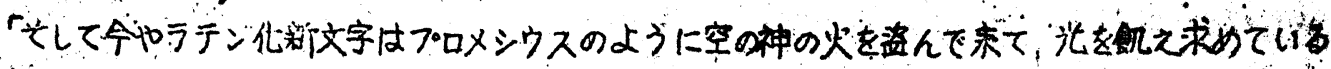

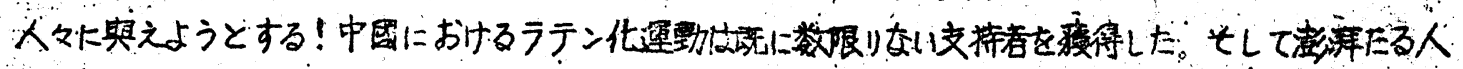

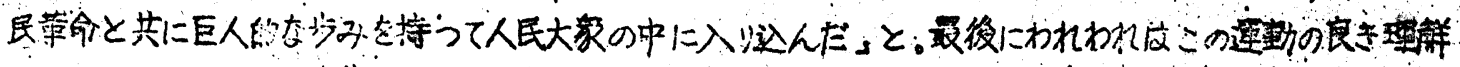

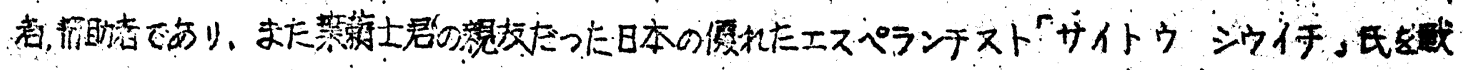

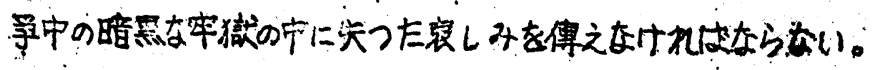

\section{梁落超の文体：中村 忠行}

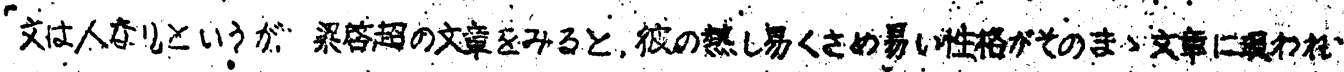

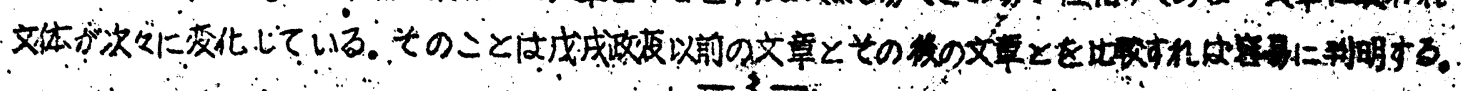

